\title{
Erdheim chester disease presenting as bone pain with a lytic lesion: Case history and review of the literature
}

\author{
Alexander H Jinnah ${ }^{1}$, Shadi A Qasem ${ }^{2}$, Cynthia L Emory*1 \\ ${ }^{1}$ Department of Orthopaedic Surgery, Wake Forest School of Medicine, Winston-Salem, USA \\ ${ }^{2}$ Department of Pathology, Wake Forest School of Medicine, Winston-Salem, USA
}

Received: December 29, 2015

Accepted: February 2, 2016

Online Published: Feburary 18, 2016

DOI: $10.5430 /$ jst.v6n1p 87

URL: http://dx.doi.org/10.5430/jst.v6n1p87

\begin{abstract}
Erdheim Chester Disease (ECD) is characterized by organ infiltration by CD68 positive and CD1a negative non-Langerhans Histiocytes. The presentation of ECD can vary from bone pain due to bone infiltration to multi-systemic forms involving the cardiovascular system. The prognosis of ECD is poor; however, with increased understanding of the pathogenesis, this has led to the evolution of new therapeutic strategies.

Because of the increased need for understanding this disease we present a case of a man, who presented to us with bone pain and radiographs showing a lytic lesion in his left femur. Upon further investigation with magnetic resonance (MR) imaging and technetium $99 \mathrm{~m}$ bone scan we chose to undergo an open biopsy, which led to the definitive diagnosis. We outline the current treatment regimen and its evolution as our understanding of the pathogenesis of ECD has increased.
\end{abstract}

Key Words: Erdheim chester disease, Orthopaedic oncology, non-Langerhans Histiocytosis, Lytic lesion, Bone

\section{INTRODUCTION}

Erdheim Chester Disease (ECD), first described by Jakob Erdheim's pupil William Chester, is a rare non-Langerhans Histiocytosis. ${ }^{[1]}$ This disease is characterized by organ infiltration by CD68 positive and CD1a negative non-Langerhans histiocytes. ${ }^{[1]}$ Due to the rarity and various presentations of ECD, misdiagnosis is common, however, can be disastrous if lesions infiltrate systemically leading to pathological fractures, cardiovascular and central nervous system involvement. ${ }^{[1]}$ Moreover, the overall prognosis is poor but if ECD is diagnosed and addressed with proper treatment the 5-year survival rate has been reported as $68 \% .^{[1]}$ Herein, we present the case of a gentleman with ECD and discuss the importance of having a high clinical suspicion for this rare disease.

\section{Case PResentation}

A 49-year-old male presented to the office for evaluation of leg pain in conjunction with abnormal radiographic findings in his left tibia, femur, shoulder and bilateral clavicles. The patient reported pain in his left knee and shoulder for almost eighteen months. He also had chronic lower back pain for approximately ten years, unchanged from baseline. Upon presentation to the office he endorsed a 4-6 weeks' history of bilateral hip pain which worsened with activity. Initial evaluation at an outside facility consisted of radiographs, advanced imaging, and subsequent referral to our center. His relevant past medical history is significant for stroke, mixed hyperlipidemia, sacroiliitis and generalized osteoarthritis.

Physical exam revealed a stable left knee with full range

\footnotetext{
* Correspondence: Cynthia L Emory, MD; Email: clemory@ wakehealth.edu; Address: Medical Center Blvd, Department of Orthopaedic Surgery, Wake Forest School of Medicine, Winston-Salem, NC, USA.
} 
of motion, and tenderness of the anterior and lateral joint. Right hip examination demonstrated anterior tenderness with normal strength, but limited internal and external rotation. Left hip and neurological examinations were unremarkable.
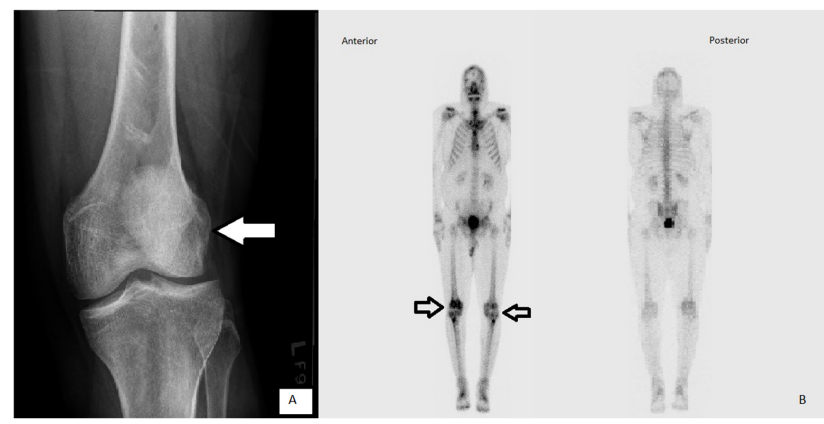

Figure 1. AP plain radiograph (A) of the left knee shows osteosclerosis of the distal femoral metaphysis (arrow). Bone scan (B) showing increased uptake bilaterally in the distal femur and proximal tibia.

Initial radiographs showed a lytic lesion of the left femoral neck, without endosteal scalloping. Furthermore, sclerosis was seen in the distal femoral metaphysis (see Figure 1A) which corresponded to increased scintigraphic uptake on bone scan along with other sites of osseous involvement (see Figure 1B). Magnetic resonance (MR) imaging illustrated low signal within the bone marrow of the distal femur and proximal tibia on T1-weighted imaging (see Figure 2A) and hyperintense signal on T2-weighted imaging (see Figure 2B). With these imaging findings, we recommended open biopsy of the left distal femur.

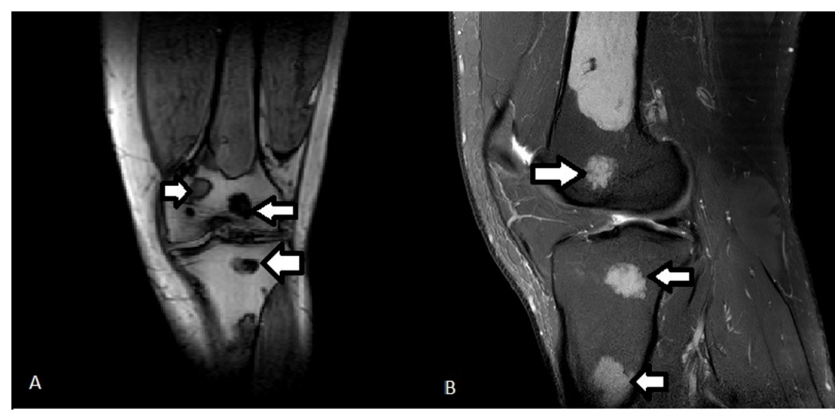

Figure 2. (A) Coronal T1 weighted image and (B) sagittal T2 weighted image, showing infiltration of the fatty bone marrow (arrows) in the distal femur and proximal tibia.

The bone biopsy showed a mixed histiocytic and lymphoplasmacytic infiltrate with foamy macrophages. Histiocytes were the predominant cell type with abundant clear to pink cytoplasm. Furthermore, the histiocytes were positive for
CD68 and negative for CD1a, cytokeratin, and S100 (see Figure 3). There was no mutation found in the BRAF gene, which is reported to be present in a large proportion of ECD cases. ${ }^{[1]}$ However, it is important to note that there have been reported cases of ECD without the BRAF mutation. [1] With these findings the diagnosis of ECD was made. He was subsequently referred to a medical oncologist where he was started on treatment with interferon-alpha. The patient is now eight months from his initial presentation to our clinic and is tolerating the treatment well.

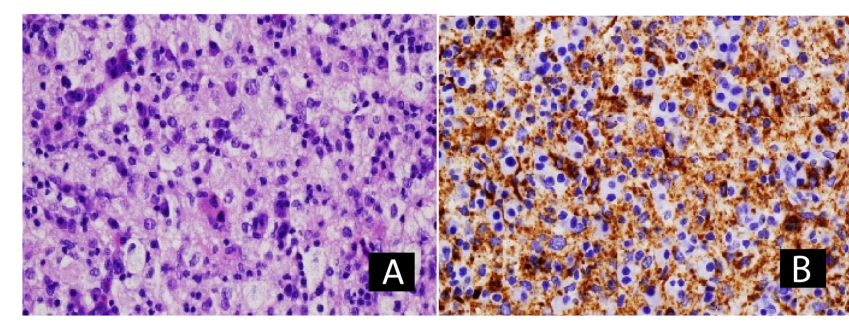

Figure 3. High power view $(40 \times)$ with hematoxylin and eosinophil stain (A) showing a mixture of lymphocytes and plasma cells with abundant foamy histiocytes in the background. High power view $(40 \times)$ of CD68 immunohistochemical stain (B) highlighting the histiocytes.

\section{DiscuSSION}

ECD, first described by Jakob Erdheim's pupil William Chester in 1930, has been reported just over 500 times in the English literature. ${ }^{[1,2]}$ ECD is a rare neoplastic disorder characterized by infiltration of CD68 positive and CD1a negative non-Langerahns foamy histiocytes or macrophages into various tissues. ${ }^{[1-4]}$ The characteristic cells seen on histology are multinucleated with nuclei organized in a wreathlike ring and xanthomatous cytoplasm, also known as Touton-like giant cells. ${ }^{[5-7]}$ The presentation can be extremely variable based on the broad distribution of lesions. The skeleton is affected in $90 \%$ of patients, but virtually every organ may be involved. ${ }^{[1]}$ Thus, clinical manifestation can vary from an incidental finding on radiographs, as in this case, to a multisystemic life-threatening disease. ${ }^{[8]}$ Interestingly, in our case the typical osteosclerosis of the diaphyseal and metaphyseal regions of the long bones associated with ECD was not present. ${ }^{[9]}$ However, with appropriate biopsy the final diagnosis was made. Despite this disease having been recognized over eighty years ago, the pathogenesis is not yet fully clear. $^{[1]}$

\subsection{Pathogenesis}

Although the pathogenesis remains elusive, there have been recent advances in the understanding of this complex disease. Several authors have demonstrated the presence of 
a local and systemic pro-inflammatory network, and hence have postulated that this is responsible for recruitment and activation of histiocytes into ECD lesions. ${ }^{[1,10]}$ Not surprisingly, interleukin (IL)-6, is a strongly expressed cytokine in biopsies of ECD patients. It is believed that this is the fundamental cytokine involved in the pathogenesis of ECD due to its involvement in osteoclastic differentiation leading to osteosclerosis, a hallmark of the disease. ${ }^{[1]}$ Additionally, as with many oncologic diseases, there is a suspected genetic component to ECD.

Furthermore, recent data shows that ECD can be characterized by high levels of interferon-alpha, IL-12, monocyte chemotactic protein 1 and lower levels of IL-4 and IL-7. ${ }^{[1]}$ This discovery has led to the starting point of the current therapeutic strategy that is in practice today.

\subsection{Treatment strategies}

Treatment of patients with ECD included steroids, cytotoxic agents, and double autologous hematopoietic stem cell transplantation until 2005. ${ }^{[4,11,12]}$ However, these treatments were generally considered to be either ineffective or have only transitory efficacy. ${ }^{[5,7]}$ In 2005 Braiteh et al. published a study of three cases of ECD treated with interferon-alpha and described a long lasting effect using this method. ${ }^{[5]}$ The authors described rapid regression of retro-orbital infiltration and a gradual improvement in bone lesions. Moreover, a recent case series and review of the literature by Haroche $e t$ al. concluded that interferon-alpha was the preferred initial treatment for ECD as this treatment was a major independent predictor of survival. ${ }^{[4]}$ The rationale of interferon alpha stems from induction of terminal differentiation of the histiocytes. ${ }^{[13]}$ Additionally, there have been several trials of different targeted cytotoxic treatments in recent years due to the increased understanding of the pathogenesis of ECD; however, the results have been conflicting. ${ }^{[4,14-16]}$

One potential treatment strategy that has had an increasing interest is the use of BRAF inhibitors, Vemurafenib and Dabrafenib. ${ }^{[1,3]}$ This would not have been relevant to our patient due to the lack of a BRAF mutation; however, due to the high association seen between a BRAF mutation and ECD, we expect this to become an integral part of most treatment plans for ECD. Furthermore, these inhibitors have been shown to dramatically improve clinical and radiographic outcomes. ${ }^{[17,18]}$ Despite these promising results, further studies are needed to establish the role of the BRAF mutation in the pathogenesis of ECD.

\section{Conclusion}

In conclusion, with the recent increase in understanding of ECD, new treatments have been implemented with better potential outcomes, albeit, with limited results to this point. Recent advances in treatment of ECD warrants a review of the disease etiology and presentation so it is not omitted in the differential diagnosis of a patient with multiple bone lesions.

\section{CONFLicts OF INTEREST Disclosure}

The author declares that there is no conflict of interest statement.

\section{REFERENCES}

[1] Campochiaro C, Tomelleri A, Cavalli G, et al. Erdheim-Chester disease. European journal of internal medicine. 2015; 26: 2239. PMid:25865950. http://dx.doi.org/10.1016/j.ejim. 20 15.03 .004

[2] Haroche J, Amoura Z, Dion E, et al. Cardiovascular involvement, an overlooked feature of Erdheim-Chester disease: report of 6 new cases and a literature review. Medicine. 2004; 83: 37192. PMid:15525849. http://dx.doi.org/10.1097/01.md.000 0145368.17934 .91

[3] Cives M, Simone V, Rizzo FM, et al. Erdheim-Chester disease: a systematic review. Critical reviews in oncology/hematology. 2015; 95: 1-11. PMid:25744785. http://dx.doi.org/10.1016/j.cri trevonc. 2015.02.004

[4] Haroche J, Arnaud L, Cohen-Aubart F, et al. Erdheim-Chester disease. Rheumatic diseases clinics of North America. 2013; 39: 299311. PMid:23597965. http://dx.doi.org/10.1016/j.rdc.2 013.02 .011

[5] Braiteh F, Boxrud C, Esmaeli B, et al. Successful treatment of Erdheim-Chester disease, a non-Langerhans-cell histiocytosis, with interferon-alpha. Blood. 2005; 106: 2992-4. PMid:16020507. http: //dx.doi.org/10.1182/blood-2005-06-2238

[6] Ivan D, Neto A, Lemos L, et al. Erdheim-Chester disease: a unique presentation with liver involvement and vertebral osteolytic lesions. Archives of pathology \& laboratory medicine. 2003; 127: e337-9. PMid:12873197.

[7] Bisceglia M, Cammisa M, Suster S, et al. Erdheim-Chester disease: clinical and pathologic spectrum of four cases from the Arkadi M. Rywlin slide seminars. Advances in anatomic pathology. 2003; 10: 160-71. PMid:12717118. http://dx.doi.org/10.1097/00125 480-200305000-00004

[8] Arnaud L, Hervier B, Neel A, et al. CNS involvement and treatment with interferon-alpha are independent prognostic factors in ErdheimChester disease: a multicenter survival analysis of 53 patients. Blood. 2011; 117: 2778-82. PMid:21239701. http://dx.doi.org/10. 1182/blood-2010-06-294108

[9] Veyssier-Belot C, Cacoub P, Caparros-Lefebvre D, et al. ErdheimChester disease. Clinical and radiologic characteristics of 59 cases. Medicine. 1996; 75: 157-69. PMid:8965684. http://dx.doi.org /10.1097/00005792-199605000-00005 
[10] Stoppacciaro A, Ferrarini M, Salmaggi C, et al. Immunohistochemical evidence of a cytokine and chemokine network in three patients with Erdheim-Chester disease: implications for pathogenesis. Arthritis and rheumatism. 2006; 54: 4018-22. PMid:17133532. http://dx.doi.org/10.1002/art. 22280

[11] Myra C, Sloper L, Tighe PJ, et al. Treatment of Erdheim-Chester disease with cladribine: a rational approach. The British journal of ophthalmology. 2004; 88: 844-7. PMid:15148234. http: //dx.doi.org/10.1136/bjo.2003.035584

[12] Boissel N, Wechsler B, Leblond V. Treatment of refractory ErdheimChester disease with double autologous hematopoietic stem-cell transplantation. Annals of internal medicine. 2001; 135: 844-5. PMid:11694122. http://dx.doi.org/10.7326/0003-4819-1 35-9-200111060-00027

[13] Luft T, Luetjens P, Hochrein H, et al. IFN-alpha enhances CD40 ligand-mediated activation of immature monocyte-derived dendritic cells. International immunology. 2002; 14: 367-80. PMid:11934873. http://dx.doi.org/10.1093/intimm/14.4.367

[14] Janku F, Amin HM, Yang D, et al. Response of histiocytoses to imatinib mesylate: fire to ashes. Journal of clinical oncology: official journal of the American Society of Clinical Oncology. 2010; 28: e633-6. PMid:20733125. http://dx.doi.org/10.1200/JC0.2 010.29 .9073

[15] Haroche J, Amoura Z, Charlotte F, et al. Imatinib mesylate for platelet-derived growth factor receptor-beta-positive ErdheimChester histiocytosis. Blood. 2008; 111: 5413-5. PMid: 18502845. http://dx.doi.org/10.1182/blood-2008-03-148304

[16] Aouba A, Georgin-Lavialle S, Pagnoux C, et al. Rationale and efficacy of interleukin-1 targeting in Erdheim-Chester disease. Blood. 2010; 116: 4070-6. PMid:20724540. http://dx.doi.org/10.11 82/blood-2010-04-279240

[17] Cohen-Aubart F, Emile JF, Maksud P, et al. Marked efficacy of vemurafenib in suprasellar Erdheim-Chester disease. Neurology. 2014; 83: 1294-6. PMid:25171932. http://dx.doi.org/10.1212/WNL .0000000000000832

[18] Haroche J, Cohen-Aubart F, Emile JF, et al. Dramatic efficacy of vemurafenib in both multisystemic and refractory Erdheim-Chester disease and Langerhans cell histiocytosis harboring the BRAF V600E mutation. Blood. 2013; 121: 1495-500. PMid:23258922. http://dx.doi.org/10.1182/blood-2012-07-446286 